\title{
Vineyard-specific climate projections help growers manage risk and plan adaptation in the Paso Robles AVA
}

\begin{abstract}
Fine-scale resolution climate change projections help communicate risk and facilitate adaptive responses among viticulturalists in the Paso Robles AVA.
\end{abstract}

by Nicholas Babin, Jazlyn Guerrero, Diego Rivera and Ajay Singh

Online: https://doi.org/10.3733/ca.2021a0019

\section{Abstract}

California's wine grape growers will face increasing challenges under a changing climate as most production occurs near the boundaries of current varieties' climatic thresholds. As part of this study, we developed a method for transforming downscaled climate information from the publicly available Cal-Adapt database into useful and useable climate projections for vineyard managers and advisors in the Paso Robles American Viticultural Area. We shared vineyard-specific projections during interviews of 20 managers and advisors. Overall, interviewees expressed trust in the projections and found them helpful in reducing their psychological distance from climate change. The projections prompted consideration of strategies for managing future climate risk and planning adaptation, with the majority of adaptations associated with long-term decisions such as row orientation, variety selection, dry farming, crop diversification and relocation. Agri-climatic decision support tools such as the one prototyped here may prove especially helpful for incorporating climate adaptation into the long-term business planning and vineyard redevelopment decisions facing managers and advisors in the near future. This approach could be extended to other California wine grape regions or to other perennial crops with expected vulnerabilities to climate change.
- The Paso Robles American Viticultural Area (AVA) features approximately 40,000 planted acres and over 200 wineries that generate US $\$ 1.9$ billion in total annual output value and provide over 13,000 jobs in northern San Luis Obispo County (Matthews and Medellin-Azuara 2016). The AVA is known for high-quality red wine production dominated by the varieties cabernet sauvignon, merlot and zinfandel. Climate change will affect both yield and quality of wine grape production in the Paso Robles AVA. Impacts on grape yields are projected to be relatively low compared to other major California commodities, with an estimated $10 \%$ yield reduction by 2100 (Pathak et al. 2018). However, impacts on grape quality will be more severe, as projected water shortages, prolonged heat waves and increasing average growing-season temperatures will likely damage harvests and shift the ripening potential beyond a threshold for many of the varieties currently being grown in the region (Jones et al. 2005). Adaptation to climate change is thus increasingly recognized as crucial for the sustainability of the Paso Robles AVA and other California wine grape growing sectors (Nicholas and Durham 2012).

Modifying row orientation to protect vines from the afternoon sun is an important redevelopment decision that can make vineyards more resilient to projected increases in average temperatures and extreme heat events. Photo: Nicholas Babin. 
The production span for wine grapes is 20 to 50 years, meaning that planning, designing and implementing adaptation measures may benefit from climate change decision support systems (CCDSSs), which Palutikof et al. (2019) define as "knowledge resources that facilitate decision-making for adaptation to climate change." CCDSSs can provide useful and usable climatic projections for agriculture (Prokopy et al. 2017). The goal of this study was to evaluate the potential of Cal-Adapt, a web-based CCDSS, as an aid in communicating risk and developing adaptation strategies for the changing climate in the Paso Robles AVA.

\section{Climate change and agriculture}

Research on farmer perceptions of climate change reveals deep differences depending on locale and cropping system. While $66 \%$ of Midwestern U.S. corn producers believe climate change is occurring, only $22 \%$ believe it is a threat to agriculture (Arbuckle et al. 2013). Meanwhile, 53\% of New Zealand wine grape growers believe climate change is occurring but fully $32 \%$ believe it is a threat to agriculture (Niles et al. 2015). One potential explanation for these divergent perceptions is that different cropping systems, climates and national contexts have rendered some groups more psychologically distanced from the impacts of climate change than others. The theory of psychological distance asserts that the more geographically and temporally distant the perceived impacts of an event, the less willing individuals are to make personal decisions addressing the issue (Spence et al. 2012). Based on this theory, risk communication techniques, including CCDSSs, have been developed that effectively reduce psychological distance and increase public engagement with issues related to climate change (Jones et al. 2017).

While extensive effort has been dedicated to develop CCDSSs specific to the needs of Midwestern grain farmers (Angel et al. 2017), these tools have been under-exploited in other U.S. agricultural sectors, including viticulture (Mase and Prokopy 2014). Where CCDSSs have been utilized, boundary organizations that mediate between CCDSS producers (scientists) and users (farmers) have been identified as key in increasing usability (Lemos et al. 2012; Prokopy et al. 2015). Relevant boundary organizations within the California agriculture sector include the Natural Resource Conservation Service (NRCS), resource conservation districts (RCDs) and UC Cooperative Extension. Viticulturalists might be especially willing to utilize CCDSSs; a survey of European wine grape growers found that $93 \%$ desired more information on the projected future impacts of climate change on wine grapes (Battaglini et al. 2009). Additionally, a survey of Australian grape growers found that $72 \%$ indicated that the uncertainty surrounding future climate change would not stop them from considering climate change when making decisions about adapting their practices (Dunn et al. 2015).
Cal-Adapt is a publicly accessible, web-based CCDSS maintained by the University of California, Berkeley, that provides localized climate projections produced by California's scientific and research community (Cal-Adapt 2021). Cal-Adapt provides historical climate data as well as projection tools, including "Extreme Heat," "Sea Level Rise," "Annual Averages" and "Extended Drought" to help guide local adaptation decisions. Projections can be made over any time interval between current day and 2099, can utilize either low (representative concentration pathway [RCP] 4.5) or high (RCP 8.5) emission scenarios, can employ any combination of ten global climate models and can be generated at multiple spatial scales from the level of an entire county down to a grid measuring 6 kilometers by 6 kilometers. This fine scale of spatial resolution makes the tools much more useful for viticultural adaptation than the coarser resolution projections generally available, as wine-producing regions often feature extensive topographical and microclimatological variability (Mosedale et al. 2016).

While the potential of the Cal-Adapt tool for reducing psychological distance and promoting adaptation in viticulture is high, past usage has focused on city and regional planning efforts and not the agricultural sector (Deas 2015). This study evaluated the potential of the Cal-Adapt tool for risk communication and climate adaptation among viticulturalists. Specifically, we addressed the following questions:

1. What short-term general risks (1 to 2 years), longterm general risks ( 3 to 20 years), and climaticspecific risks to viticulture are most important to vineyard managers and advisors in the Paso Robles AVA?

2. What climate change risks and adaptations are considered by managers and advisors after reviewing a vineyard-specific projection generated from Cal-Adapt?

3. How can the Cal-Adapt decision support system be improved for viticulturalists?

\section{Interview framework}

The Paso Robles AVA of northern San Luis Obispo County is characterized by a hot-summer Mediterranean climate and is relatively dry; since 1942, the city of Paso Robles has had an average annual rainfall of 14.2 inches (Paso Robles Water Division 2020). Groundwater is the main source of irrigation water in the AVA, and the majority of planted acres lie within a groundwater basin classified by the Sustainable Groundwater Management Act (SGMA) as high priority and critically overdrafted (Battany and Tindula 2018). We compiled an initial interviewee list of three vineyard managers and three advisors in consultation with a local grape grower organization, and we used a snowball sampling method to identify additional subjects (Schutt 2014). The managers we interviewed were owner-operators, estate employees or management
The production span for wine grapes is 20 to 50 years, meaning that planning, designing and implementing adaptation measures may benefit from climate change decision support

systems... 
TABLE 1. Variables and temporal frames utilized in vineyard specific Cal-Adapt projections for two vineyards in the Paso Robles AVA

\begin{tabular}{|c|c|c|c|}
\hline Climatic variable & Time frame & Westside vineyard & Eastside vineyard \\
\hline \multirow{3}{*}{$\begin{array}{l}\text { Annual average days } \\
>95^{\circ} \mathrm{F}\end{array}$} & $1961-1990^{*}$ & 7.0 & 38.0 \\
\hline & 2020-2039† & 20.0 & 64.0 \\
\hline & 2050-2070† & 35.0 & 85.0 \\
\hline \multirow{3}{*}{$\begin{array}{l}\text { Annual average days } \\
>100^{\circ} \mathrm{F}\end{array}$} & $1961-1990^{*}$ & 0.0 & 16.0 \\
\hline & 2020-2039† & 5.0 & 38.0 \\
\hline & 2050-2070† & 12.0 & 54.0 \\
\hline \multirow{3}{*}{$\begin{array}{l}\text { Annual average days } \\
>105^{\circ} \mathrm{F}\end{array}$} & $1961-1990^{*}$ & 0.0 & 3.0 \\
\hline & 2020-2039† & 1.0 & 13.0 \\
\hline & 2050-2070† & 3.0 & 25.0 \\
\hline \multirow{3}{*}{$\begin{array}{l}\text { Annual average 4-day } \\
\text { heatwaves }>100^{\circ} \mathrm{F}\end{array}$} & $1961-1990^{*}$ & 0.0 & 1.0 \\
\hline & 2020-2039† & 0.2 & 3.6 \\
\hline & 2050-2070† & 1.0 & 7.6 \\
\hline \multirow{3}{*}{$\begin{array}{l}\text { Annual average } \\
\text { longest stretch of days } \\
>100^{\circ} \mathrm{F}\end{array}$} & 1961-1990* & 0.4 & 4.1 \\
\hline & 2020-2039t & 2.0 & 8.4 \\
\hline & 2050-2070† & 4.1 & 12.3 \\
\hline \multirow{3}{*}{$\begin{array}{l}\text { Annual average nights } \\
\text { minimum temp }>60^{\circ} \mathrm{F}\end{array}$} & 1961-1990* & 4.0 & 4.0 \\
\hline & 2020-2039† & 17.0 & 12.0 \\
\hline & 2050-2070† & 41.0 & 36.0 \\
\hline \multirow{3}{*}{$\begin{array}{l}\text { Annual average } \\
\text { maximum }{ }^{\circ} \mathrm{F}\end{array}$} & $1961-1990^{*}$ & 71.5 & 76.1 \\
\hline & 2020-2039† & 74.2 & 79.2 \\
\hline & 2050-2070† & 77.0 & 82.1 \\
\hline \multirow{3}{*}{$\begin{array}{l}\text { Annual average } \\
\text { minimum }{ }^{\circ} \mathrm{F}\end{array}$} & 1961-1990* & 40.3 & 42.1 \\
\hline & 2020-2039† & 42.9 & 45.1 \\
\hline & 2050-2070† & 45.4 & 47.6 \\
\hline \multirow{3}{*}{$\begin{array}{l}\text { Annual average inches } \\
\text { of rain }\end{array}$} & $1961-1990 *$ (range) & $26.1(11-48.5)$ & $11.9(5.3-24.2)$ \\
\hline & 2020-2039† (range) & $27.9(9.4-58.7)$ & $13.6(4.7-26.2)$ \\
\hline & $2050-2070 \dagger$ (range) & $27.2(5.1-4.4)$ & $13.1(2.2-40.9)$ \\
\hline
\end{tabular}

RCP 8.5 emissions scenario and four-model average utilized for projections.

* Observed.

† Projected.
(Church et al. 2018). Following these initial interview questions, we presented each interviewee with a paper copy containing, in both narrative and tabular form, a downscaled $(6 \mathrm{~km} \times 6 \mathrm{~km}$ resolution) vineyardspecific projection from Cal-Adapt. If the interviewee was a vineyard manager, the location we selected for the downscaled projection was the vineyard's primary grape-growing site. If the interviewee was an advisor, we chose a location that the advisor had experience advising. The interviewer read through the entire projection with the interviewee, stopping as needed for clarification. Finally, interviewers asked interviewees how, if at all, the downscaled, vineyard-specific projections from Cal-Adapt changed their perception of risks and whether it made them consider adaptation measures.

The full range of climatic variables and timeframes we generated and shared with interviewees can be found in the left-hand column of table 1. (Table 1 also presents results for two of the 20 vineyards we studied. These two vineyards, located only 12 miles apart, epitomize the increasing severity of projected climate change as one travels west to east across the microclimates of the Paso Robles AVA.) We obtained the projections before the interviews took place using the "Annual Averages," "Extreme Heat" and "Extended Drought" tools from the Cal-Adapt web portal (CalAdapt 2021). We used the four-model average and RCP 8.5 emissions scenarios. Figure 1 contains screen captures from the Cal-Adapt website and illustrates the overall process we used to obtain projections. In addition, we developed an instructional video and template that contains step-by-step instructions for generating an agriculturally relevant projection using Cal-Adapt. This video can be found at https://tinyurl. com/climateprojection.

In-person interviews lasted between one and two hours and were digitally recorded and professionally transcribed. The resulting transcripts were uploaded into the qualitative software package NVIVO (version 12; QSR International, Burlington, Mass.) for coding and analysis. We then reviewed the transcripts and suggested themes to use as a coding framework within NVIVO. Next, we selected four interview transcripts (two advisors and two managers) for each researcher to code within NVIVO, which resulted in a coding agreement of $80 \%$. Following discussion, the coding framework was revised and a subsequent coding round resulted in 95\% coding agreement (Mouter and Vonk Noordegraaf 2012). Table 2 shows the revised coding framework we used when analyzing the 20 interview transcripts. The 11 vineyard manager transcripts were then coded by one researcher while the nine advisor transcripts were coded by another researcher. The summary results and exemplar quotes presented below represent the dominant themes in the analysis. 


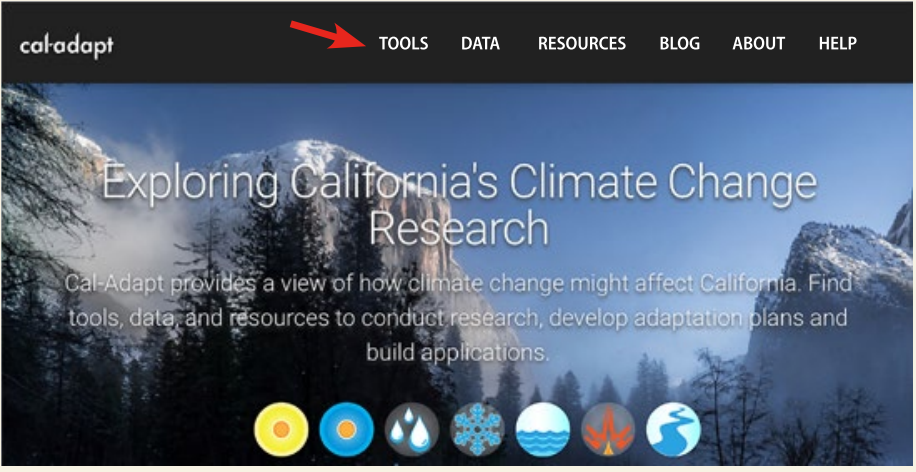

FIG. 1A. Cal-Adapt homepage. Once at the homepage, click on the "TOOLS" tab in the top right.

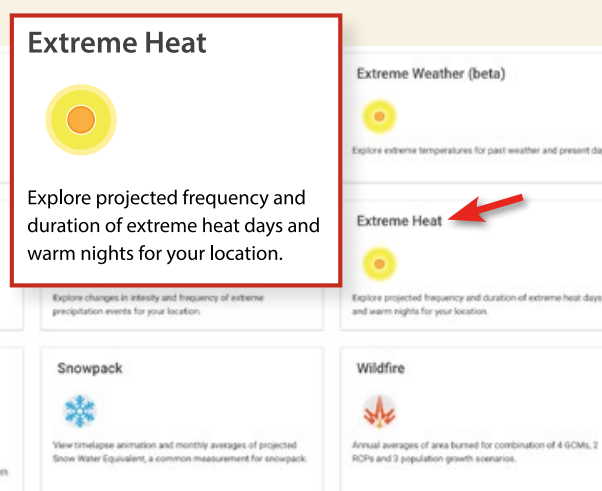

FIG. 1B. Tools on the Cal-Adapt tools page can be activated by clicking.
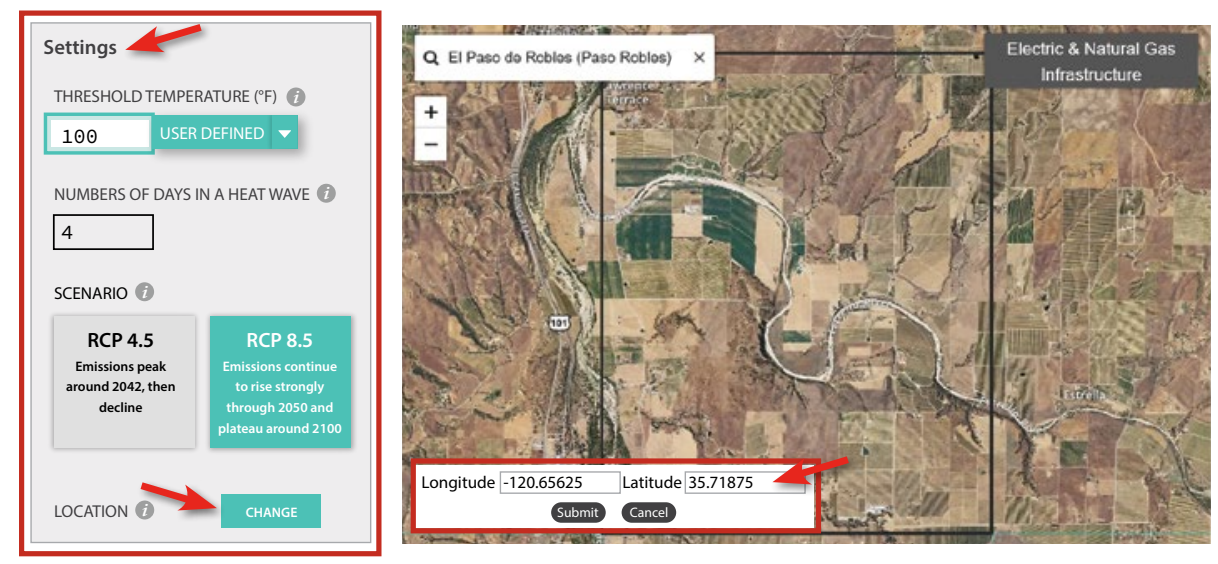

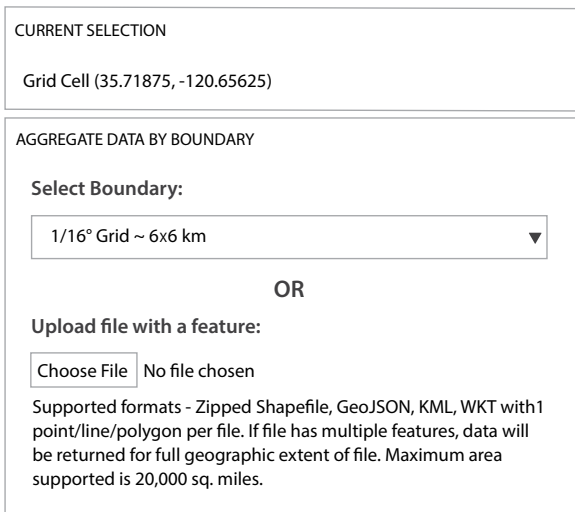

FIG. 1C. Once a specific tool is chosen, the scale of projection can then be selected. Scale options include counties, watersheds and $6 \mathrm{~km} \times 6 \mathrm{~km}$ plots. A sample $6 \mathrm{~km} \times 6 \mathrm{~km}$ grid projection is shown here.

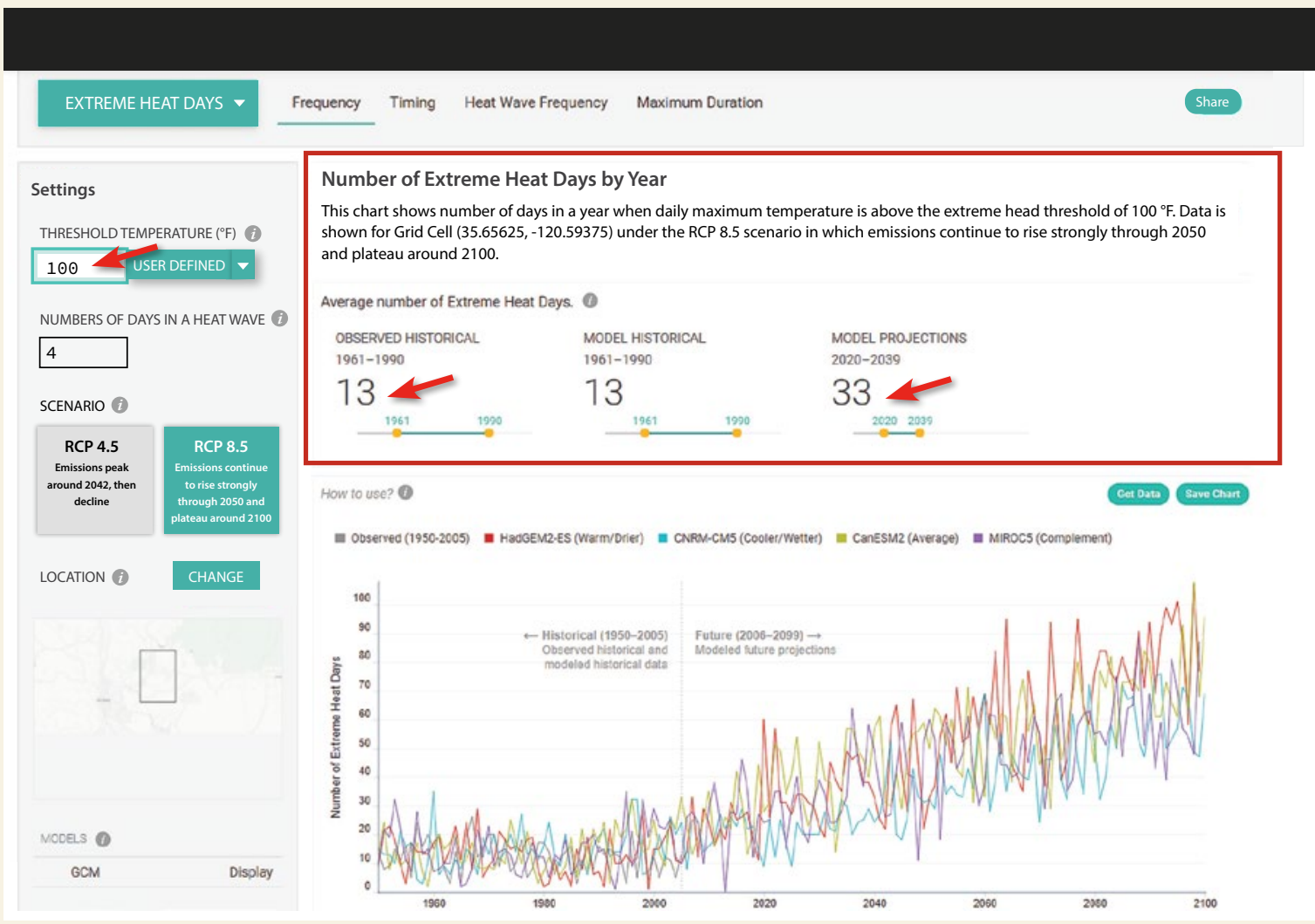

FIG. 1D. Extreme heat results for a Paso Robles vineyard indicate that this particular vineyard experienced an average of 13 days per year of temperatures over $100^{\circ} \mathrm{F}$ between 1961 and 1990 and that it is projected to experience temperatures over $100^{\circ} \mathrm{F}$ for an average of 33 days per year from 2020 to 2039 . 
TABLE 2. Coding framework

\begin{tabular}{|c|c|c|c|}
\hline $\begin{array}{l}\text { Risks (short- and } \\
\text { long-term) }\end{array}$ & $\begin{array}{l}\text { Climate change } \\
\text { risks }\end{array}$ & $\begin{array}{l}\text { Downscaled } \\
\text { projections }\end{array}$ & $\begin{array}{l}\text { Climate change } \\
\text { risk management }\end{array}$ \\
\hline $\begin{array}{l}\text { - Labor } \\
\text { - Water } \\
\text { - Market } \\
\text { - Regulations } \\
\text { - Disease or pests } \\
\text { - Input costs } \\
\text { - Climate or weather }\end{array}$ & $\begin{array}{l}\text { - Water availability } \\
\text { - Extreme heat } \\
\text { - Growing degree } \\
\text { change } \\
\text { - Erosion } \\
\text { - Grape quality } \\
\text { - Pests } \\
\text { - Phenology } \\
\text { - Yields } \\
\text { - Frosts }\end{array}$ & $\begin{array}{l}\text { - Overall response } \\
\text { - Risks } \\
\text { - Adaptations } \\
\text { - Improvements }\end{array}$ & $\begin{array}{l}\text { - Current practices } \\
\text { to reduce risk } \\
\text { - Potential practices } \\
\text { to reduce risk } \\
\text { - Short-term } \\
\text { farming and } \\
\text { winemaking } \\
\text { adaptations } \\
\text { - Long-term } \\
\text { diversification } \\
\text { and vineyard } \\
\text { design } \\
\text { adaptations }\end{array}$ \\
\hline
\end{tabular}

TABLE 3. Unprompted short-term risk perceptions over the next 2 years

\begin{tabular}{|l|c|c|}
\hline \multicolumn{1}{|c|}{ Risk } & Manager $(n=11)$ & Advisor $(n=9)$ \\
\hline Labor & $7(64 \%)$ & $4(44 \%)$ \\
\hline Market oversupply & $6(55 \%)$ & $6(67 \%)$ \\
\hline Diseases/pests & $6(55 \%)$ & $3(33 \%)$ \\
\hline Water supply & $5(45 \%)$ & $7(78 \%)$ \\
\hline Regulations & $4(36 \%)$ & $4(44 \%)$ \\
\hline Climate/weather volatility & $3(27 \%)$ & $4(44 \%)$ \\
\hline
\end{tabular}

Number of interviewees who mentioned risk is followed by percentage of all interviewees from each group.

TABLE 4. Unprompted long-term risk perceptions over the next 3 to 20 years

\begin{tabular}{|l|c|c|}
\hline Risk & Manager $(n=11)$ & Advisor $(n=9)$ \\
\hline Water supply & $6(55 \%)$ & $4(44 \%)$ \\
\hline Regulations & $5(45 \%)$ & $3(33 \%)$ \\
\hline Diseases/pests & $4(36 \%)$ & $1(11 \%)$ \\
\hline Labor & $3(27 \%)$ & $3(33 \%)$ \\
\hline Climate weather volatility & $3(27 \%)$ & $5(56 \%)$ \\
\hline Market oversupply & $1(9 \%)$ & $3(33 \%)$ \\
\hline
\end{tabular}

Number of interviewees who mentioned risk is followed by percentage of all interviewees from each group.

TABLE 5. Prompted climate change risks

\begin{tabular}{|l|c|c|}
\hline Risk & Manager $(n=11)$ & Advisor $(n=9)$ \\
\hline Extreme heat events & $9(82 \%)$ & $8(89 \%)$ \\
\hline Water availability & $8(73 \%)$ & $8(89 \%)$ \\
\hline Seasonal shifts & $4(36 \%)$ & $5(56 \%)$ \\
\hline Frosts & $4(36 \%)$ & $2(22 \%)$ \\
\hline Pests & $0(0 \%)$ & $7(78 \%)$ \\
\hline
\end{tabular}

Number of interviewees who mentioned risk is followed by percentage of all interviewees from each group.

\section{Unprompted risk perception}

Only one-quarter of vineyard managers identified climate or weather volatility as risks in the short- and long-term, compared to about half of advisors (tables 3 and 4). Labor, market oversupply and diseases and pests were the most frequently identified unprompted short-term risks by vineyard managers, while market oversupply and water supply were the most frequently cited short-term risks by advisors. In the long-term, market oversupply and regulations were the most mentioned risks by vineyard managers, while climate and weather volatility was the most common risk mentioned by advisors.

When asked to identify the climate change risks most concerning to viticulture in the Paso Robles AVA, vineyard managers identified extreme heat events and water availability as being the most significant (table 5). Advisors identified extreme heat events, water availability and pests as being the most concerning.

\section{Projections and risk perception}

The Cal-Adapt projections we shared with interviewees contained narrative expositions of the climate variables found in table 1 . The most frequently identified risks prompted by this information were those associated with the effect of increased average temperatures and heat waves on wine quality. The following quotes exemplify reactions among vineyard managers (VMs) and vineyard advisors (VAs).

We already are on the edge of quality grapes due to our high-heat wave, low-humidity events ... and so this projected change absolutely is going to harm our great quality and our yield which then harms our profitability. - VM 6

We're already a hot area... So if it gets any warmer than that, we're kind of getting out of the realm of quality wine production. - VM 5

If this occurs we would probably end up with not quite as flavorful wines as we're growing now. VM 7

This is going to affect my ability to ripen the grapes. It's going to be crazy to have a hotter summer. And the fruits not ripening because they've been too hot and they haven't been able to process properly. - VM 4

The negative feedback of higher temperatures on water usage was noted and was compounded by uncertainty surrounding future water availability due to potential SGMA-related pumping restrictions.

I get nervous about the heat spikes and water as a resource. - VM 8

You start getting into long days of 105, 108, and stuff like that... If you see those coming, you're going to want to water it. So it's going to up your water usage. - VM 10

Back to water. Absolutely, that's the biggest risk. $-V M 2$ 
Vineyard managers and their advisors from the east side of the AVA displayed more severe risk perception than those from the west side.

So east Paso is the one that has the highest temperatures. Right? Like more extreme weather. West Paso is very different. They get a lot of rain. So I think east Paso will be more susceptible. - VA 2

The linkage between climate change and increased pest pressure was widely acknowledged by advisors but not managers, indicating an area of future research, outreach and education.

\section{Projection-prompted adaptations}

Adaptation responses prompted by Cal-Adapt projections overwhelmingly focused on long-term as opposed to short-term measures. However, some short-term measures were discussed; these included increased use of shade cloths, spray-shield products, misting, improving irrigation efficiency and targeted pruning.

Long-term adaptations, especially those associated with potential vineyard redevelopment, dominated interview conversations and included measures such as changing grape variety, rootstock, vine spacing, row orientation, trellising systems, dry farming, relocation and diversification out of grapes.

Any sort of vineyard design, row orientation, solar interception... So maybe you're redeveloping a vineyard and you change the row orientation. VM 6

Row orientation, and maybe trellis system and maybe pruning system. So long-term decisions, not short-term decisions. - VA 6

It'll definitely change the way we have to grow grapes here. I mean, look for a northern slope versus a southern slope. - VM 7

Advisors were adamant that, to grow quality grapes in the climate projected, varieties other than cabernet sauvignon, merlot and zinfandel would need to be explored.

Variety selection, trying to find varieties that certainly do well, or at least avoiding the ones that we know are going to be disasters with the high temperatures. - VA 7

By far I'm going to tell you that the best possibility, particularly thinking long-term, it has to do with the choice of the variety. - VA 6

We've been kind of boxed in to mostly French varieties... it wouldn't surprise me at all if heattolerant varieties became more of a thing. - VA 3
Despite the fact that new varieties might perform better in the projected future climate, both advisors and managers recognized that the marketing of unknown varieties from a region steeped in name recognition and tradition would be a challenge, especially in the current situation of oversupply and low prices.

Over time as a vineyard comes out, let's say in five years, that person now has a choice. What do I put in? What looks to be most acceptable? And for them, their biggest deterrent is going to be, what does the winery want to buy? What will somebody give me a contract for?... The new varieties have unusual names and the growers are not going to produce them until there's a shift in taste in the consumer. So that's where we have kind of painted ourselves into a corner if the consumer only says I want to buy cabernet. - VA 7

I love different varieties. I did my whole masters on that. But no, you're locked in. You're already in an oversupply market. I don't need to create 30 new varieties that no one has ever heard of. They can't even sell the line they have. - VM 6

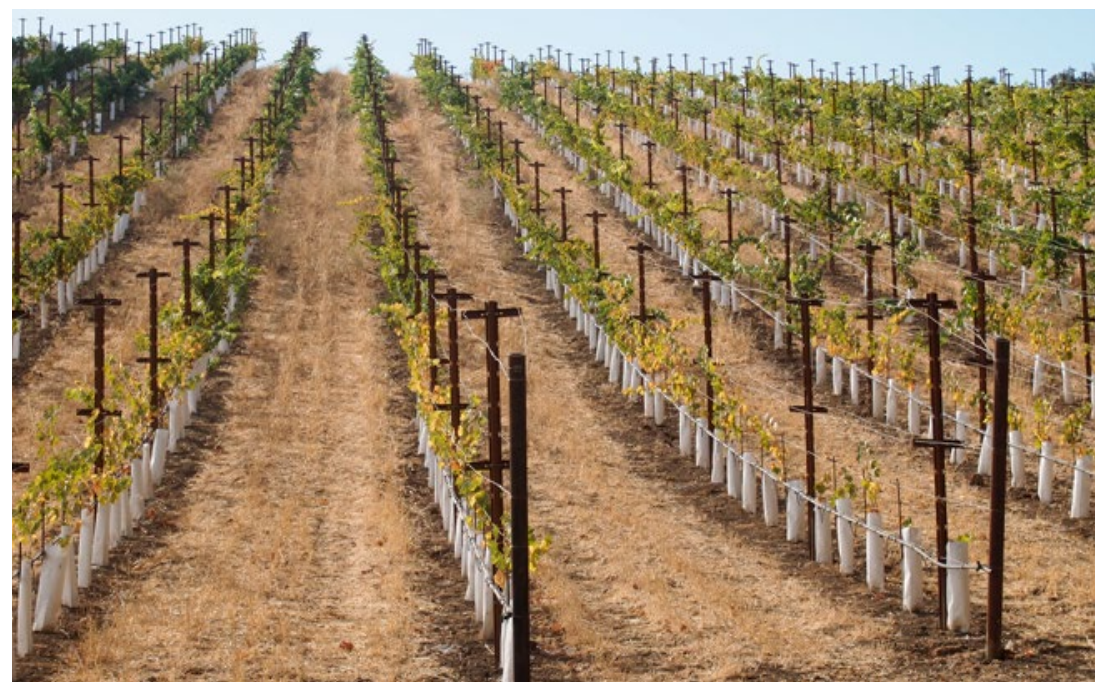

Vineyard redevelopment in the Paso Robles AVA. As vineyards are planted new or redeveloped, long-term adaptations can be introduced, such as changing grape variety, rootstock, vine spacing, row orientation and trellising systems. Photo: Nicholas Babin.

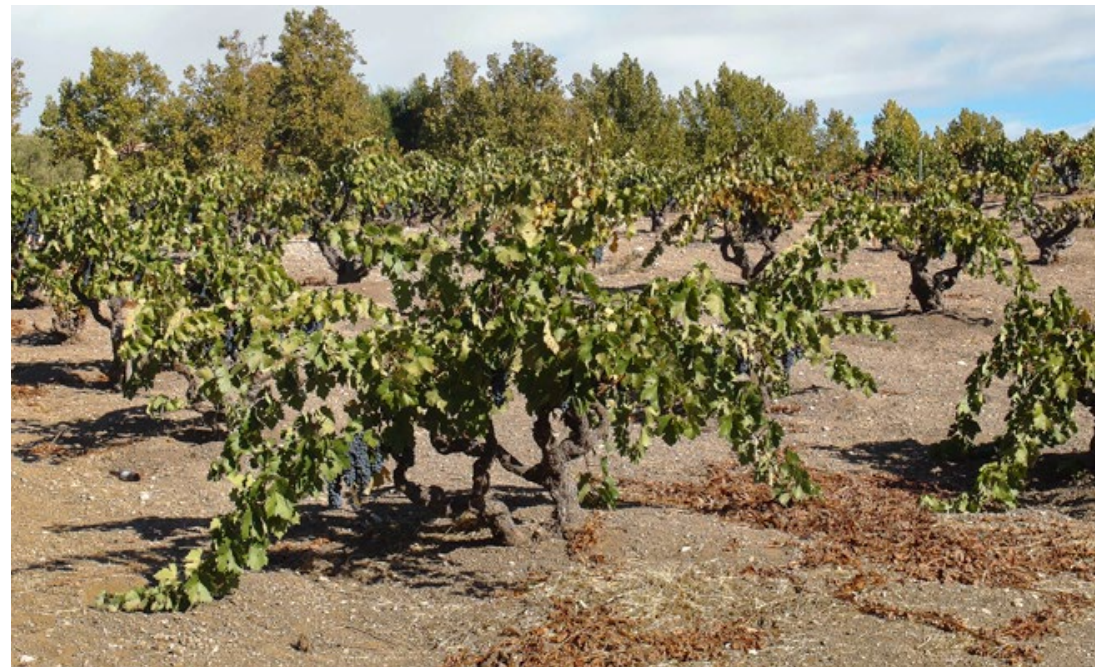

The dry farming of grapes is one potential strategy for conserving water in the critically overdrafted Paso Robles Watershed Subbasin. Photo: Nicholas Babin. 
Advisors observed that production of the varieties that currently dominate the Paso Robles AVA would probably shift to other regions, underscoring the need to develop consumer acceptance for new varieties.

If the climate is like this, then there's going to be a new Paso somewhere else... So Paso could shift up, north, or further south, depending on what makes sense... there's going to be a new area that that takes over because Paso is done. - VA 4

Several advisors noted that larger, corporate estate vineyards are already planning for this shift. This illustrates that while climate change will be a challenge for some grape-growing locales, it will present opportunities for others.

Those larger corporate investor types who are planning long-term, managing finances are saying, "Okay, long term, some of this is looking a little sketchy." They'll run the same scenario up in Idaho or Washington and say that looks pretty good. VA 6

The very large companies are skeptical of the Central Coast. Based on long-term projections of heat and water scarcity... They're not bullish on the Central Coast, that was in the '90s. Now they're shying away from it. - VA 7

The Cal-Adapt projections, when combined with the current oversupply market, prompted some managers to consider diversification out of viticulture on either part or all of their vineyards.

We may be growing something completely different in this area. Thirty years ago, there weren't all these vineyards around. They were growing alfalfa. And they were growing almonds. And they were growing other things. And so why grapes here? Because they worked so well. But it was an adaption to the area. And that could change. - VM 9

I think you'd have to adapt to other crops... I just don't know what that is. I don't have answers right now. - VM 8

One of our growers was talking about the glut of cab sauvignon. And someone was asking him, "So if I was replanting, what should I plant then? What variety should I plant?" He said, "Almonds." So it just could be that that we've reached a saturation point. - VA 4

Finally, several managers who were also owner-operators discussed the possibility of selling their vineyards so that they could either retire or relocate.
Hopefully, I would have sold my vineyard by then. Yeah, maybe that's what I need to do, is get out of this business. I don't need to go to Vegas anymore. All my gambling urges and risk-taking are completely locked down by farming. - VM 4

The best-case scenario is still a scary scenario. I don't know if people understand that... If it was an owner-operator guy, he might say, "I can't do anything with this. I'm going to sell my property and get out of here." - VA 4

\section{Reactions to the Cal-Adapt tool}

While none of the advisors expressed skepticism toward the validity of the projections, three out of the 11 managers did. The dramatic increase in extreme heat days in the projections may have shocked some into disbelief.

I think I'm not buying in to this assumption. I think I would buy more of this assumption if the impacts were less severe. This becoming Death Valley is hard for my brain. - VM 8

However, when we included downscaled past annual average temperatures, extreme heat frequencies and precipitation totals that managers perceived as being historically accurate, they expressed greater confidence in the validity of the projections. Future sharing of projections could more extensively involve the validation of historic vineyard level data generated by Cal-Adapt as a strategy for building vineyard manager trust in the projections. This, in turn, could lead to an increased willingness to include climate projections in vineyard risk management and adaptation planning.

Looking out at 2100, it's hard to fathom just from a glance at the map. This [vineyard-specific projection] actually helped, putting it localized to a ranch that we're familiar with. I could see where it makes sense as far as the amount of past days over 100 and rainfall. Those numbers actually seem to track. And they resonate with me here. So I think that if that's what these are based on, then the projection's probably got some validity to it. I'm very curious to go and plug in some other addresses and see what pops up. - VM 9

Overall, interviewees' impressions of the projection tool were positive. Several vineyard managers commented that the personalized narrative projections were more helpful than coarse-resolution, map-based projections.

I think putting a number to the heat waves and the narrative is very helpful. The physical maps I think people see quite a bit but having someone be able to read it is a fairly powerful way to present it. - VM 6 


\section{Bridging psychological distance}

By making risks seem less distant and diffuse over space and time, CCDSSs like Cal-Adapt promise to help bridge the psychological distance associated with climate change (Spence et al. 2012). This could prove especially valuable for outreach among workers in the agricultural sector, who tend to view the potential impacts of climate change skeptically.

If this was to be true I'd definitely be more proactive about mitigating risk. - VM 8

Climate change is a real thing. It's a big deal. It's really a big deal. - VM 1

I'm finding that more and more people are willing to admit that it's a problem, and they're trying to find mitigation measures for that. - VA 4

Several interviewees mentioned that the utilization of climate projections and adaptation forecasting was more likely to be employed by large corporate estate vineyards with the time and resources to invest in comprehensive planning and asset evaluation, rather than by small owner-operator contract growers.

We need more of a commitment to helping the smaller-scale growers, because they're less likely to have the resources to be able to deal with this. VA 7

What happens if you grow just one variety, and you're small, and you're dependent on selling to a winery, and all of a sudden your variety goes downhill from climate change? - VA 3

There is a prospective role here for boundary organizations such as RCDs, UC Cooperative Extension, wine sustainability organizations (e.g., The Vineyard Team and the California Sustainable Winegrowing Alliance) and small-producer organizations (e.g., Independent Grape Growers of the Paso Robles Area, Paso Robles Wine Country Alliance) for further training in and utilization of the Cal-Adapt tool. These boundary organizations are natural constituencies for transforming the publicly available data into useable information, for example, during resource-planning exercises and outreach activities.

\section{Barriers to adaptation}

Suggested adaptations inspired by the projections focused both on long-term practices implemented during redevelopment and on relocation. As mentioned above, however, prior to the sharing of the projections the majority of vineyard managers did not include climate change as a significant long-term risk. Indeed, climate change was mentioned as only one among many risks they are managing, demonstrating the multiple dimensions of risk exposure inherent in commercial agriculture (Belliveau et al. 2006). Advisors and managers shared that their general approach to managing risk in viticulture is to tackle issues as they arise.

I know and care about climate change, but I listed a number of factors before I got to that ... I mean, it would be nice if you could be truly strategic and be thinking forward, but in a lot of cases, it's kind of a hand-to-hand combat figuring out what you're going to sell this year, trying to make as good a decision as you can about the next year. - VM 11

I'm just trying to navigate day by day, year by year. $-V M 8$

It's just this mentality of only being able to deal with one to two years or one to a couple of things at a time. - VA 4

This just-in-time approach may prove to be a fundamental barrier in adopting needed viticultural adaptation practices during redevelopment.

\section{Improving Cal-Adapt projections}

Interviewees requested that future iterations of the tool include extreme cold events during the growing season, growing season average temperatures and growing degree-days as projection outputs. This information, they maintained, could assist them in selecting new grape varieties or other crops that may be more appropriate to grow in the future. Interviewees also indicated that projected budbreak and harvest dates would be useful additions. Due to widespread concerns over the impacts of extreme heat and drought on vine stress, interviewees also recommended including the variables of soil moisture and evapotranspiration. These two variables could be included in future Cal-Adapt iterations as a composite indicator, such as climatic water deficit, which quantifies the amount of evaporative demand exceeding available soil moisture.

From a current-user standpoint, we found the projection generation process cumbersome. The tool was not designed for agricultural use, so it took quite a while to become acquainted with the many options for projection generation and to learn how to narrow in on those most relevant for viticultural decision-making. Then we had to convert the numeric indicators generated by Cal-Adapt into narrative form so that the projection was clearer and more easily conveyed to interviewees. This also meant that the process was somewhat lengthy (about 30 minutes per projection). However, the breadth of highly detailed and free data available from Cal-Adapt is a potential boon for the agricultural sector, and many of these issues could be addressed by the creation of a plugin tool that automatically generates in a narrative form variables and indicators relevant to agriculture. 


\section{Conclusions}

Cal-Adapt has significant potential for improving risk communication and promoting climate change adaptation strategies among viticulturalists in the Paso Robles AVA. The unprompted solicitation of risks during this research revealed that, at the present time, most managers don't consider climate change an important risk and, for those who do consider it a risk, it often isn't a priority. Risk management includes identifying, evaluating and prioritizing risks. Actions can then be taken to minimize risk probability and impact or to maximize opportunities. However, managers can't manage for risks that they haven't identified as existing. The Cal-Adapt projections showed promise in reducing the psychological distance of climate change perceived by vineyard managers and advisors. This has the potential to increase growers' willingness to utilize climate projection data for long-term risk management and adaptation planning purposes (Jones et al. 2017). In order to be truly useful and useable, key climatic variables need to be included and the tool's web-based navigation should be improved. There is a role for boundary organizations in improving, employing and promoting this CCDSS in their work with managers so they can better evaluate and address risks from climate change (Lemos et al. 2012). Long-term planning processes are already a part of managing a perennial crop such as wine grapes, and Cal-Adapt projections should be included in these processes to facilitate longterm redevelopment decisions.
The interaction between stable or declining average annual rainfall and increased heat will stress water resources in this already critically overdrafted basin. Past research has estimated vineyard irrigation water usage in the Paso Robles AVA (Battany and Tindula 2018); future research should determine the current extent of water efficiency bestmanagement practice adoption on vineyards in the region. Future research should also identify the barriers and opportunities for more widespread adoption of soil and water conservation practices that will make vineyards more resilient to the projected impacts of climate change. In addition, because small, owner-operated growers may be more vulnerable to the impacts of climate change than larger corporate entities, future outreach and support should focus on improving the adaptive capacity of the small-scale producers. This will be crucial in ensuring the long-term sustainability of grape production in the region. CA

\begin{abstract}
N. Babin is Assistant Professor, J. Guerrero is Master's Student, and D. Rivera is Master's Student, Natural Resources Management and Environmental Sciences Department, California Polytechnic State University, San Luis Obispo; and A. Singh is Assistant Professor, Department of Environmental Studies, California State University, Sacramento.

This research was supported by funding from the USDA McIntire-Stennis Cooperative Forestry Research Program and the Agricultural Research Institute of the
\end{abstract} California State University.

\section{References}

Angel JR, Widhalm M, Todey $D$, et al. 2017. The U2U corn growing degree day tool: Tracking corn growth across the US Corn Belt. Clim Risk Manag 15:73-81. https://doi.org/10.1016/j. crm.2016.10.002

Arbuckle JG, Prokopy LS, Haigh T, et al. 2013. Climate change beliefs, concerns, and attitudes toward adaptation and mitigation among farmers in the

Midwestern United States. Clim Change 117(4):943-50. https:// doi.org/10.1007/s10584-0130707-6

Battaglini A, Barbeau G, Bindi M, Badeck FW. 2009. European winegrowers' perceptions of climate change impact and options for adaptation. Reg Environ Change 9(2):61-73. https://doi.org/10.1007/s10113 008-0053-9

Battany M, Tindula G. 2018. Paso Robles vineyard irrigation study provides benchmark data to assist future area groundwater management. Calif Agri 72(1):76-83. https://doi. org/10.3733/ca.2018a0003

Belliveau S, Smit B, Bradshaw B. 2006. Multiple exposures and dynamic vulnerability: evidence from the grape industry in the Okanagan Valley, Canada. Glob Environ Change 16(4):364-78. https://doi.org/10.1016/j.gloenvcha.2006.03.003
Cal-Adapt. 2021.About CalAdapt. Geospatial Innovation Facility at UC Berkeley. California Energy Commission, Sacramento, CA. https://cal-adapt. org/about/

Church SP, Dunn M, Babin N, et al. 2018. Do advisors perceive climate change as an agricultural risk? An in-depth examination of Midwestern US Ag advisors' views on drought, climate change, and risk management. Agric Human Values 35(2):349-65. https://doi. org/10.1007/s10460-017-9827-3

Deas MS. 2015. Cal-Adapt and the usability of climate adaptation tools. Master's Thesis, Department of Urban Studies and Planning, Massachusetts Institute of Technology, Cambridge MA.

Dunn MR, Lindesay JA, and Howde M. 2015. Spatial and temporal scales of future climate information for climate change adaptation in viticulture: a case study of User need in the Australian winegrape sector. Aust J Grape Wine Res 21(2): 226-39. https://doi. org/10.1111/ajgw.12138

Jones C, Hine DW, Marks AD. 2017. The future is now: reducing psychological distance to increase public engagement with climate change. Risk Anal 37(2):331-41. https://doi. org/10.1111/risa.12601
Jones GV, White MA, Cooper OR, Storchmann K. 2005. Climate change and global wine quality. Clim Change 73(3):319-43. https://doi.org/10.1007/s10584 005-4704-2

Lemos MC, Kirchhoff CJ, Ramprasad V. 2012. Narrowing the climate information usability gap. Nat Clim Change 2(11):789-94. https://doi. org/1038/NCLIMATE1614

Mase AS, Prokopy LS. 2014. Unrealized potential: A review of perceptions and use of weather and climate information in agricultural decision making. Weather Clim Soc 6(1):47-61. https://doi.org/10.1175/WCAS D-12-00062.1

Matthews WJ, Medellín-Azuara J. 2017. The Economic Impacts of the San Luis Obispo County and Paso Robles AVA Wine Industry. Agricultural Issues Center, UC Davis. 38 p.

Mosedale JR, Abernethy KE, Smart RE, et al. 2016. Climate change impacts and adaptive strategies: lessons from the grapevine. Glob Change Biol 22(11):3814-28. https://dol. org/10.1111/gcb.13406
Mouter N, Vonk Noordegraaf DM 2012. Intercoder reliability for qualitative research: You win some, but do you lose some as well? Proceedings of the 12th TRAIL Congress, Oct. 20-31, 2012. Rotterdam, Netherlands. Delft, Netherlands: TRAIL Re search School.

Nicholas KA, Durham WH. 2012. Farm-scale adaptation and vulnerability to environmental stresses: Insights from winegrowing in Northern California. Glob Environ Change 22(2):48394. https://doi.org/10.1016/] gloenvcha.2012.01.001

Niles MT, Lubell M, Brown M. 2015. How limiting factors drive agricultural adaptation to climate change. Agric Ecosyst Environ 200:178-85. https://doi. org/10.1016/j.agee.2014.11.010 Palutikof JP, Street RB, Gardiner EP. 2019. Decision support platforms for climate change adaptation: an overview and introduction. Clim Change 153:459-76. https://doi. org/10.1007/s10584-01902445-2

Paso Robles Water Division 2020. Rainfall totals, 1942-2019. El Paso de Robles, Department of Public Works. www.prcity. com/462/Rainfall-Totals (accessed Oct. 9, 2020).
Pathak TB, Maskey ML, Dahlberg JA, et al. 2018. Climate change trends and impacts on California agriculture: a detailed review. Agronomy 8(3):25. https://doi.org/10.3390/agronomy 8030025

Prokopy LS. 2011. Agricultural human dimensions research: The role of qualitative research methods. J Soil Water Conserv 66(1):9A-12A. https://doi. org/10.2489/jswc.66.1.9A

Prokopy LS, Carlton JS, Arbuckle JG, et al. 2015. Extension's role in disseminating information about climate change to agricultural stakeholders in the United States. Clim Change 130(2):261-72. https://doi. org/10.1016/j.jenvp.2014.12.004

Prokopy LS, Carlton JS, Haigh T, et al. 2017. Useful to usable: Developing usable climate science for agriculture. Clim Risk Manag 15:1-7. https://doi. org/10.1016/j.crm.2016.10.004

Schutt RK. 2014. Investigating the social world: The process and practice of research. 8th Edition. Thousand Oaks, CA: Sage Publications, Inc. 688 p.

Spence A, Poortinga W, Pidgeon N. 2012. The psychological distance of climate change. Risk Analysis3 32(6):957-72. https://doi.org/10.1111/j.15396924.2011.01695.x 